\title{
Family hardiness, anxiety, and subjective well-being in families with and without a chronic illness
}

\section{Introduction}

Many families face a chronic illness during the family life cycle. From the family's point of view, a chronic illness presents a stressful experience for the whole family and impacts on patients' and family members' psychological well-being, especially when a child is stricken with it. The functioning and well-being of the family have been related to the family's resilience, which is defined as the family's ability to recover from adversity, to protect the family unit from major disruptions during periods of a chronic illness and to recover

* Tanja Pate is a doctor of sciences (a PhD degree in 2014) as well as a marriage and family therapist. She is a researcher and an assistant professor at the Faculty of Theology, University of Ljubljana, Slovenia, where she works as an assistant in the marriage and family studies master's program and the advanced studies program of marriage and family therapy. Her scientific and research papers on chronic illness, family stress and biopsychosocial/spiritual model of health and illness have been published in Slovenia and abroad.

* Miha Pate graduated from theology in 2011. He is a doctoral student in the program of marriage and familytherapy at the Faculty of Theology, University of Ljubljana, as well as a marriage and family therapist intern at the Franciscan Family Institute in Ljubljana, Slovenia. 
from that experience. ${ }^{1}$ The way that such capabilities and strengths develop is related to the prevailing climate of relationships and interactions within the family, which is family hardiness. ${ }^{2}$

Hardiness is defined as an individual's belief in their own ability to thrive in the face of high levels of stress, and to influence the management of life. ${ }^{3}$ It covers both cognitive as well as behavioral aspects of personality characteristics that determine the way how individuals react in stressful situations. Family hardiness is the flexibility factor which refers to the inner strength and durability of the family ${ }^{4}$ and has been recognized as a mediator in the relation between illness, stress, and strain as well as the quality of life and health of all family members. ${ }^{5}$ Family hardiness is characterized by a sense of control over life events; active and engaged coping, as well as adaptation to stressful life situations. Family hardiness includes the family's commitment and joint cooperation in responding to stress; confidence in the ability to deal with problems in terms of family cohesion and support, and a feeling that the family has control over a stressful situation. In the Resiliency Model of Family Stress, Adjustment and Adaptation, ${ }^{6}$ family adaptation to a stressor event such as having a family member with a chronic illness is viewed as occurring in two phases over time: adjustment and adaptation. In the

1 B. Pauline, Family stress management: a contextual approach, Newbury Park 2002, p. 75.

2 M. McCubbin, H. McCubbin, A. Thompson, FHI: Family Hardiness Index, in: Family assessment inventories for research and practice, eds. H. McCubbin, A. Thompson, Madison 1986, pp. 124-130.

3 S. Kobasa, Stressful life events, personality, and health: an inquiry into hardiness, "Journal of Personality and Social Psychology" 37 (1) (1979), pp. 1-11, http://psycnet.apa.org/psycinfo/1980-21134-001 (26.11.2016).

4 H. McCubbin, M. McCubbin, Resiliency in families: a conceptual model of family adjustment and adaptation in response to stress and crises, in: Family assessment inventories for research and practice, eds. H. McCubbin, A. Thompson, Madison 1986, pp. 1-64.

5 L. Nabors, J. Kichler, A. Brassell, et al., Factors related to caregiver state anxiety and coping with a child's chronic illness, "Families, Systems and Health. The Journal of Collaborative Family Healthcare" 2013 No. 31 (2), pp. 171-180, https://www.researchgate.net/publication/241695746_Factors_Related_to_Caregiver_State_Anxiety_and_Coping_With_a_Child's_ Chronic_Illness (26.11.2016); L. Northouse, D. Mood, T. Kershaw, A. Schafenacker, S. Mellon, J. Walker, E. Galvin, V. Decker, Quality of life of women with recurrent breast cancer and their family members, "Journal of Clinical Oncology: Official Journal of the Amercian Society of Clinical Oncology" 2002 No. 20 (19), pp. 4050-4064, https://www.researchgate.net/publication/11104767_Quality_of_Life_of_Women_With_Recurrent_Breast_Cancer_and_Their_ Family_Members (26.11.2016).

6 H. McCubbin, M. McCubbin, Resiliency in families..., pp. 1-64. 
adjustment phase, the family makes only minimal changes in its functioning; if these are not adequate to manage the stressor, a crisis occurs which signals the onset of the adaptation phase. For the family, to have a family member with a chronic illness represents the adaptation phase. The accumulation of stressors in families with chronically ill members is viewed as being managed by resiliency factors, which include changing patterns of family functioning; use of resources at the individual, family, and community level; appraisal and coping processes; and family problem solving communication.

Family strengths and resilience have received increased attention from family researchers recently. Bruce Compas with colleagues ${ }^{7}$ have indicated that parental negative coping is associated with poorer family functioning, whereas positive coping is related to better family functioning. Family hardiness is related to disease management, course, and outcome. ${ }^{8}$

This study examines the resilience factors of parental anxiety and emotional well-being as an individual resource and family hardiness as a family system resource. The research question is: How are parental anxiety, emotional well-being and family hardiness correlated? It is expected that lower anxiety and better emotional well-being would be related to higher family hardiness whereas increased anxiety and worse emotional well-being to lower family hardiness. It is also assumed that there will be significant differences regarding the presence or absence of a chronic illness in the family.

\section{Methods}

Sample

Parents were invited to participate in a cross-sectional study. The identical questionnaires for mothers and fathers that included an information sheet

7 B. Compas, S. Jaser, M. Dunn, E. Rodriguez, Coping with chronic illness in childhood and adolescence, "Annual Review of Clinical Psychology" 2012 No. 8, pp. 455-480, http://www. annualreviews.org/doi/abs/10.1146/annurev-clinpsy-032511-143108 (26.11.2016).

8 L. Nabors, J. Kichler, A. Brassell, et al., Factors related to caregiver state anxiety..., pp. 171-180; K. Woodson, S. Thakkar, M. Burbage, et al., Children with chronic illnesses: factors influencing family hardiness, "Issues in Comprehensive Pediatric Nursing" 2015 No. 38 (1), pp. 57-69, http://www.tandfonline.com/doi/abs/10.3109/01460862.2014.988896?journalCode=icpn20 (26.11.2016). 
were collected using an online survey, the URL of which was distributed via e-mail, social networks and other virtual communities.

\section{Measurements}

State Trait Anxiety Inventory (STAI) was used to determine the anxiety in parents of children and adolescents with T1D. ${ }^{9}$ The STAI differentiates state from trait anxiety. For the purpose of the study, only trait anxiety was used. Participants evaluated on a 20-item scale as to how they usually feel (1-never, 4-often). A higher score indicates a greater level of anxiety. Cronbach's alpha coefficient of the STAI trait scale in the study was 91.

The Family Hardiness Index $(\mathrm{FHI})^{10}$ is a 20 -item self-report instrument that assesses the three characteristics of hardiness identified by Kobasa: commitment, challenge and control. ${ }^{11}$ Family commitment measures the family's sense of internal strengths, dependability and ability to work together, hence the author's term "co-oriented commitment." Family challenge assesses the family's ability to be resourceful, embrace new ideas and assimilate them into their existing schemata. Control measures the family's sense of being in control of family life rather than being conditioned by external events and circumstances. The instrument requires the participant to report the degree to which a series of statements describe the family at that time using a 4-point Liker style scale, ranging through 0 (false), 1 (mostly false), 2 (mostly true) and 3 (true). Total score is derived by summing the value of all responses. Higher scores indicate greater perceived hardiness. Internal reliability for the FHI is good $(\alpha=.82)^{12}$, for each of the subscales (commitment, challenge and control) the internal reliabilities are .81, .80, and .65 (Cronbach's alpha) respectively (in this study .82, .75 and .42 (Cronbach's alpha) respectively).

9 C. Spielberger, R. Gorsuch, R. Lushene, et al., Manual for the State-Trait Anxiety Inventory, Palo Alto 1983, https://www.researchgate.net/publication/235361542_Manual_for_ the_State-Trait_Anxiety_Inventory_Form_Y1_-_Y2 (26.11.2016).

10 M. McCubbin, H. McCubbin, A. Thompson, FHI: Family Hardiness Index..., pp. 124-130.

11 S. Kobasa, Stressful life events..., pp. 1-11.

12 M. McCubbin, H. McCubbin, A. Thompson, FHI: Family Hardiness Index..., pp. 124-130. 
Subjective well-being was measured by the Positive and Negative Affect Schedule (PANAS) ${ }^{13}$ and the Satisfaction with Life Scale (SWLS). ${ }^{14}$ PANAS is a 20-item measure to assess dimensions of positive (PA) and negative affect (NA). Participants rate on a scale from 1 to 5 on how often they experience a particular emotion in general. Internal consistencies for the NA scale $(\alpha$-s from .84 to .87$)$ and for the PA scale ( $\alpha$-s from .90 to .96$)$ are "good" to "excellent," in the study sample they were $\alpha=.87$ for the NA scale and $\alpha=.84$ for the PA scale. SWLS is a 5-item instrument designed to assess respondent's cognitive evaluation of overall life. It has adequate criterion validity, good convergent and discriminant validity as well as good reliability, demonstrated in terms of high internal consistency with a value of $\alpha=.87$ and stability overtime with a test-retest coefficient of $\alpha=.82$, in the study sample $\alpha=.87$.

Sociodemographic data such as parents' gender, marital status, education level, employment status, religion and their own personal perceptions about the meaning of their faith were collected.

\section{Statistical analyses}

Frequencies, means, standard deviation $(S D)$, range and percentage distribution were calculated to describe the study sample. Bivariate correlations were calculated to examine associations between measured variables. One-way analysis of variance (ANOVA) was performed to determine the differences in measured variables between families with and without a chronic illness. The level of significance was set at .05. Statistical analyses were performed using the SPSS 21.0 statistical software package. ${ }^{15}$

13 D. Watson, L. Clark, A. Tellegen, Development and validation of brief measures of positive and negative affect: the PANAS scales, "Journal of Personality and Social Psychology" 1988 No. 54 (6), pp.1063-1070, https://www.researchgate.net/publication/235726247_Development_ and_Validation_of_Brief_Measures_of_Positive_and_Negative_Affect_The_PANAS_Scales (26.11.2016).

14 W. Pavot, E. Diener, Review of the satisfaction with life scale, "Psychological Assessment" 1993 No. 5 (2), pp. 164-172, https://internal.psychology.illinois.edu/ ediener/Documents/ Pavot-Diener_1993.pdf.

15 IBM SPSS Statistics for Windows 21.0, Armonk, New York. 


\section{Results}

Table 1: Descriptive statistics of the study sample

\begin{tabular}{|c|c|c|c|}
\hline & $\begin{array}{l}\text { Parents } \\
(\mathrm{N}=204)\end{array}$ & $\begin{array}{l}\text { Presence of chronic } \\
\text { illness in the family } \\
\qquad(N=70)\end{array}$ & $\begin{array}{l}\text { Absence of chronic } \\
\text { illness in the family } \\
\qquad(N=134)\end{array}$ \\
\hline & $\mathrm{N}(\%)$ & $N(\%)$ & $N(\%)$ \\
\hline \multicolumn{4}{|l|}{ Gender } \\
\hline Female & $153(75.0)$ & $50(71.4)$ & $103(76.9)$ \\
\hline Male & $51(25.0)$ & $20(28.6)$ & $31(23.1)$ \\
\hline \multicolumn{4}{|l|}{ Marital status } \\
\hline Married & $142(69.6)$ & $48(68.6)$ & $94(70.1)$ \\
\hline Cohabiting & $48(23.5)$ & $15(21.4)$ & $33(24.6)$ \\
\hline Single & $14(6.9)$ & $7(10.0)$ & $7(5.2)$ \\
\hline \multicolumn{4}{|l|}{ Education } \\
\hline High school or less & $83(40.7)$ & $29(41.4)$ & $54(40.3)$ \\
\hline $\begin{array}{l}\text { Bachelor's degree } \\
\text { or higher }\end{array}$ & $121(59.3)$ & $41(58.6)$ & $80(59.7)$ \\
\hline \multicolumn{4}{|l|}{$\begin{array}{l}\text { Number of children } \\
\text { in the family }\end{array}$} \\
\hline 1 & $48(23.5)$ & $12(17.1)$ & $36(26.9)$ \\
\hline 2 & $96(47.1)$ & $34(48.6)$ & $62(46.2)$ \\
\hline 3 or more & $60(29.4)$ & $24(34.3)$ & 36 (26.9) \\
\hline
\end{tabular}

Questionnaires from 204 parents were obtained. The sample mean age was 37.7 years $(S D=6.5)$. Mothers' mean age was 36.6 years $(S D=6.4)$, ranging from 20 to 55 years, fathers' was 41.1 years $(S D=5.8)$, ranging from 30 to 55 years. Seventy $(34.0 \%)$ parents reported the presence of a chronic illness in their family (Figure 1). In $13(18.6 \%)$ cases, both the child and the parent had a chronic illness, in 29 (41.4\%) cases only the child and in $25(40.0 \%)$ only the parent.

Pearson correlation coefficient showed significant parallels between study variables (Table 2). Family hardiness had a positive relation with satisfaction with life and a negative relation with anxiety in both groups of parents. Parents from families without a chronic illness and with higher family hardiness, reported a less negative affect. Additionally more children in these families were associated with higher family control and satisfaction with life and 
Figure 1: Type and frequency of a chronic illness

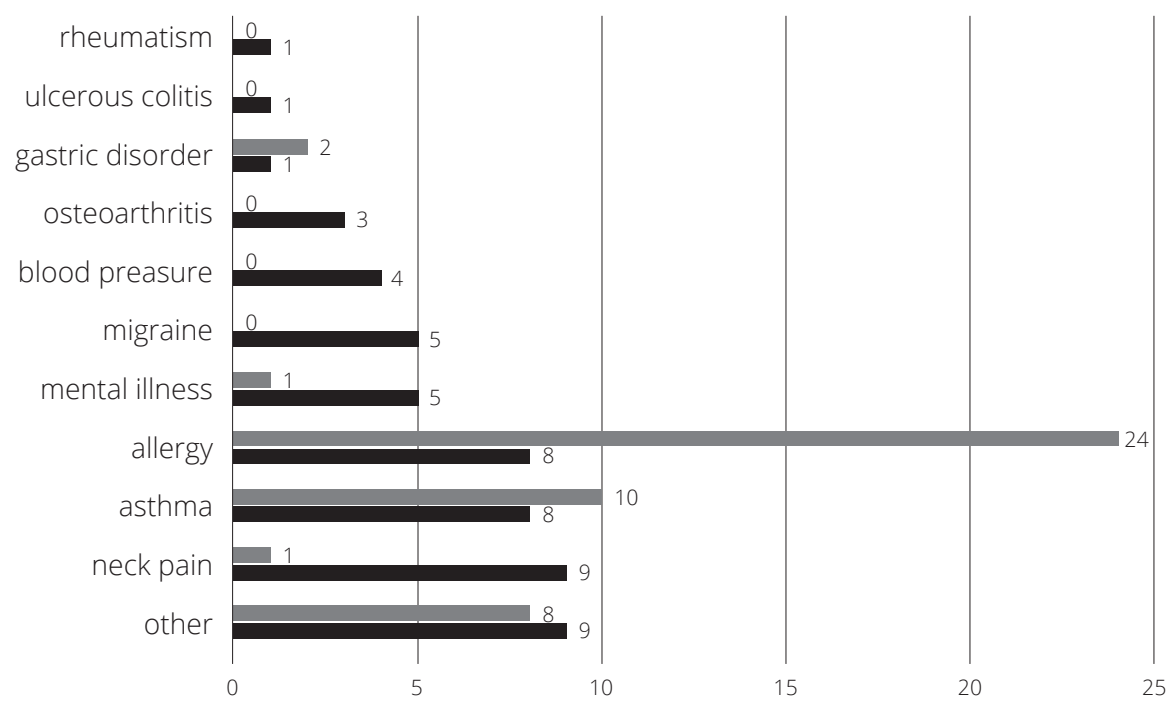

fewer negative emotions. Parental age in families with a chronic illness was negatively correlated with commitment in the family.

Table 3 gives summary statistics for study variables for the four groups of parents, regarding the presence or absence of a chronic illness in the family. The data are normally distributed, therefore means and standard deviations are reported. Further examination of study variables (one-way ANOVA) showed significant differences between the groups at the level of family hardiness $(\mathrm{F}=2.977, \mathrm{p}=.033)$ (and subscales commitment $(\mathrm{F}=3.036$, $\mathrm{p}=.030)$ and challenge $(\mathrm{F}=3.619, \mathrm{p}=.014)$, at the level of satisfaction with life $(\mathrm{F}=3.811, \mathrm{p}=.011)$ and negative affect $(\mathrm{F}=4.297, \mathrm{p}=.006)$. With regard to the presence or absence of a chronic illness in the family, post hoc multiple comparisons (LSD) showed statistically significantly higher family hardiness $(\mathrm{MD}=6.05, \mathrm{p}=.013)$ as well as family commitment $(\mathrm{MD}=3.30, \mathrm{p}=.014)$ in the group of parents without a chronic illness in the family, compared to the parents from families where both the child and the parent had a chronic illness. Furthermore, these parents also reported significantly lower family challenge compared to all other groups (only the child, $\mathrm{MD}=-2.48 \mathrm{p}=.021$; only the parent, $\mathrm{MD}=-3.27 \mathrm{p}=.003$; none $\mathrm{MD}=-2.90 \mathrm{p}=.002$ ). Parents without a chronic illness in the family had a significantly lower negative affect 


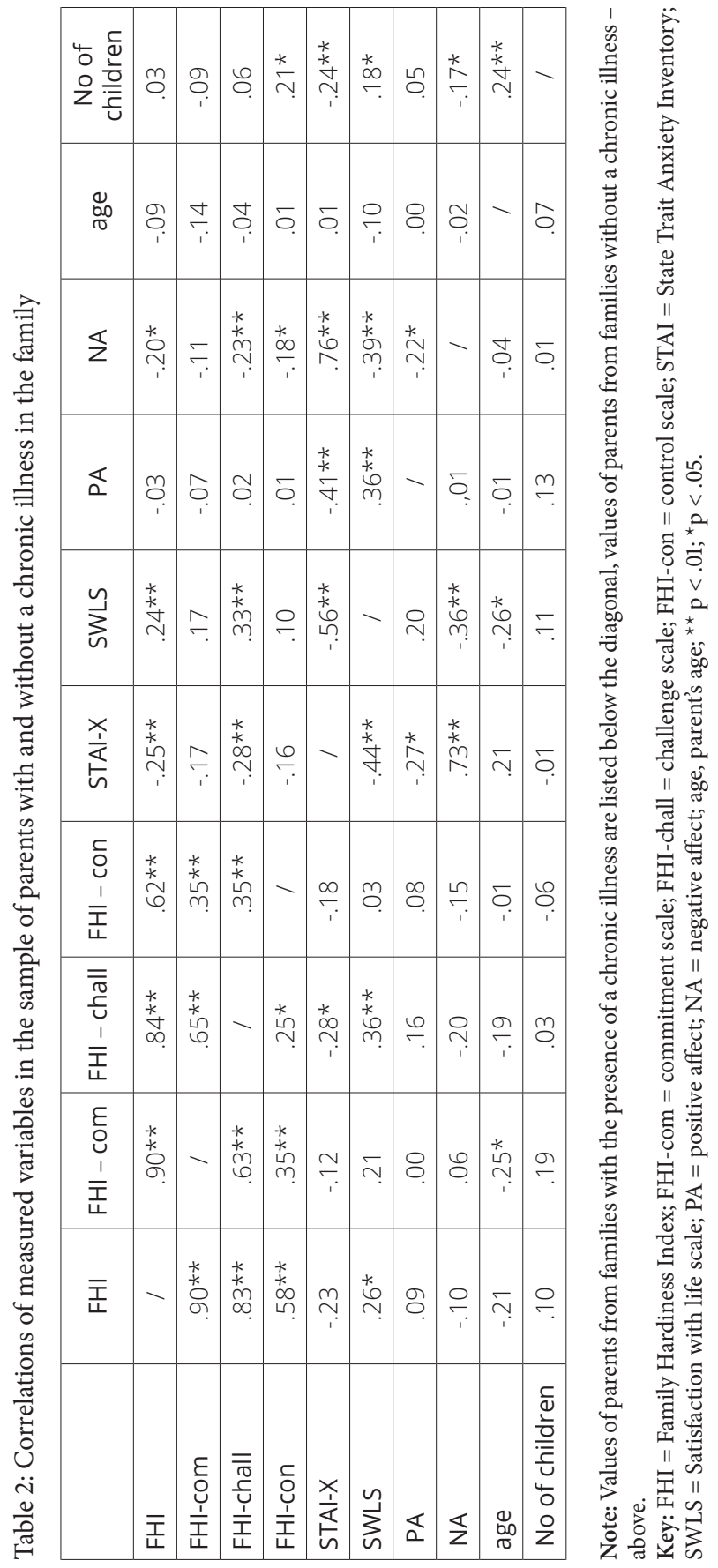


$(\mathrm{MD}=4.62 \mathrm{p}=.001)$ and higher satisfaction with life scale score $(\mathrm{MD}=3.27$ $\mathrm{p}=.005)$, compared to parents of children with a chronic illness.

Table 3. Comparison of scale scores between the groups regarding the presence of a chronic illness in the family

\begin{tabular}{|l|c|c|c|c|c|c|c|c|c|c|}
\hline \multirow{2}{*}{} & \multicolumn{2}{|c|}{$\begin{array}{c}\text { the child and } \\
\text { the parent }\end{array}$} & \multicolumn{2}{|c|}{ only the child } & \multicolumn{2}{c|}{$\begin{array}{c}\text { only the } \\
\text { parent }\end{array}$} & \multicolumn{2}{|c|}{ none } & \multicolumn{3}{|c|}{ total } \\
\cline { 2 - 12 } & $\mathrm{M}$ & $\mathrm{SD}$ & $\mathrm{M}$ & $\mathrm{SD}$ & $\mathrm{M}$ & $\mathrm{SD}$ & $\mathrm{M}$ & $\mathrm{SD}$ & $\mathrm{M}$ & SD \\
\hline FHI & 35.38 & 9.60 & 38.62 & 8.57 & 42.04 & 7.05 & 41.43 & 8.34 & 40.73 & 8.41 \\
\hline FHI-com & 14.08 & 5.14 & 15.59 & 4.74 & 17.39 & 3.68 & 17.37 & 4.65 & 16.91 & 4.64 \\
\hline FHI-chall & 9.69 & 4.59 & 12.17 & 3.17 & 12.96 & 2.94 & 12.59 & 3.09 & 12.40 & 3.25 \\
\hline FHI-con & 11.62 & 2.63 & 10.86 & 2.42 & 11.68 & 2.42 & 11.47 & 2.49 & 11.42 & 2.47 \\
\hline STAIX & 40.08 & 10.26 & 41.55 & 8.22 & 40.41 & 9.04 & 38.11 & 9.39 & 39.05 & 9.27 \\
\hline SWLS & 22.62 & 6.31 & 21.24 & 5.05 & 21.93 & 6.01 & 24.51 & 5.60 & 23.57 & 5.75 \\
\hline PA & 35.54 & 6.20 & 34.86 & 4.13 & 33.18 & 6.42 & 33.04 & 4.87 & 33.48 & 5.13 \\
\hline NA & 2354 & 7.52 & 26.71 & 6.65 & 24.43 & 7.74 & 22.10 & 6.12 & 23.16 & 6.69 \\
\hline
\end{tabular}

Key: FHI = Family Hardiness Index; FHI-com = commitment scale; FHI-chall= challenge scale; FHI-con = control scale; STAI = State Trait Anxiety Inventory; SWLS = Satisfaction with life scale; PA = positive affect; $\mathrm{NA}=$ negative affect; $\mathrm{M}=$ mean; $\mathrm{SD}=$ standard deviation.

\section{Discussion}

The major aim of this study was to examine whether family hardiness was associated with anxiety and emotional well-being in families with and without a chronic illness.

The results for the FHI total scale are in line with the results from other studies reporting moderate correlations. ${ }^{16}$ The results support the thesis that the construct of family hardiness could be seen as an indicator of family adaptation. The results supported our hypotheses since the FHI scales correlated as expected with anxiety and emotional well-being of parents from families with a chronic illness. Parents from families with a chronic

16 C. Persson, E. Benzein, K. Årestedt, Assessing family resources: validation of the Swedish version of the Family Hardiness Index, "Scandinavian Journal of Caring Sciences” 2016 No. 30 (4), pp. 845-855, http://onlinelibrary.wiley.com/doi/10.1111/scs.12313/full (26.11.2016); L. Northouse, D. Mood, T. Kershaw, et al., Quality of life of women..., pp. 4050-4064. 
illness reported lower family hardiness, more negative emotions and lower satisfaction with life. Parents who often take on full caregiving responsibilities have reported psychological and social consequences. ${ }^{17}$ Furthermore, parents who came from families where both the child and the parent had a chronic illness reported the lowest family challenge. These results suggest that the more chronic illness occupies the family, the harder it is for the family to face with challenges. Illness stresses may alter the family structure and burden the boundaries between family subsystems. ${ }^{18}$ There is no doubt that a chronic illness with its process and changes affects the family in many ways. The illness may shift relationships between family members, or between the parents themselves. The primary developmental task for the family facing a chronic illness is to create meanings that endorse mastery and capability. ${ }^{19}$ In our study, older parents from families with a chronic illness reported lower family commitment. Family members may interpret the illness experience through internalized metaphors of "weakness" or "family defects." ${ }^{20}$ Research emphasizes the recognition of the mutual influence between well-being and functioning of the family member with a chronic illness, of other family members and of the family taken as a whole. ${ }^{21}$

Family hardiness is the family's ability to work together, to be cohesive as they struggle with stressors, and to find solutions to problems, as well as

17 T. Pate, S. Klemencic, T. Battelino, N. Bratina, Fear of hypoglycemia, anxiety, and subjective well-being in parents of children and adolescents with type 1 diabetes, "Journal of Health Psychology" 2016 No. 1-10, http://www.pubpdf.com/pub/27278280/Fear-of-hypoglycemiaanxiety-and-subjective-well-being-in-parents-of-children-and-adolescents-with-t (26.11.2016).

18 J. Patterson, A. Garwick, The impact of chronic illness on families: a family systems perspective, "Annals of Behavioral Medicine" 1994 No. 16 (2), pp. 131-142, https://www.researchgate.net/publication/279547725_The_impact_of_chronic_illness_on_families_A_family_systems_perspective (26.11.2016).

19 J. Rolland, Families, illness, and disability: an integrative treatment model, New York 1994.

20 M. Cohen, Families coping with childhood chronic illness: aA research review, "Families, Systems and Health" 1999 No. 17 (2), pp. 149-164, https://www.researchgate.net/publication/232501880_Families_Coping_with_Childhood_Chronic_Illness_A_Research_Review (26.11.2016).

21 M. Brooks, Health-related hardiness and chronic illness: a synthesis of current research, "Nursing Forum" 2003 No. 38 (3), pp. 11-20, http://onlinelibrary.wiley.com/doi/10.1111/j.00296473.2003.00011.x/abstract (26.11.2016); S. Failla, L. Corson Jones, Families of children with developmental disabilities: an examination of family hardiness, "Research in Nursing \& Health" 1991 No. 14 (1), pp. 41-50, http://onlinelibrary.wiley.com/doi/10.1002/nur.4770140107/abstract (26.11.2016). 
a key variable contributing to better family functioning. Especially in times of facing and coping with a chronic illness, it may help to reestablish and support the well-being and functioning of the whole family system. Therefore, the assessment of variables predicting family functioning, family relationships and the meaning that the family attributes to the illness can provide information to assist in identifying families in need of support and those that are hardy or resilient. ${ }^{22}$ Family therapists, counselors, clinicians and other healthcare workers can support family adaptation through a wide range of interventions: reducing illness demands, increasing family resources, supporting the total family system, and enhancing family hardiness. Although this study assessed only parents, it showed the importance of further investigation at both an individual and an interactional level simultaneously.

\section{Bibliography}

Boss P., Family stress management: a contextual approach, Newbury Park 2002.

Brooks M. V., Health-related hardiness and chronic illness: a synthesis of current research, "Nursing Forum" 2003 No. 38 (3), pp. 11-20.

Cohen M. S., Families coping with childhood chronic illness: a research review, "Families, Systems and Health" 1999 No. 17 (2), pp. 149-164.

Compas B. E., Jaser S. S., Dunn M. J., Rodriguez E. M., Coping with chronic illness in childhood and adolescence, "Annual Review of Clinical Psychology" 2012 No. 8, pp. 455-480.

Failla S., Corson Jones L., Families of children with developmental disabilities: an examination of family hardiness, "Research in Nursing \& Health" 1991 No. 14 (1), pp. 41-50.

Herzer M., Vesco A., Ingerski L. M., et al., Explaining the family conflict-glycemic control link through psychological variables in adolescents with type 1 diabetes, "Journal of Behavioral Medicine" 2011 No. 34 (4), pp. 268-274.

22 B. E. Compas, S. S. Jaser, M. J. Dunn, E. M. Rodriguez, Coping with chronic illness..., pp. 455-480; M. Herzer, A. Vesco, L. M. Ingerski, et al., Explaining the family conflict-glycemic control link through psychological variables in adolescents with type 1 diabetes, "Journal of Behavioral Medicine” 2011 No. 34 (4), pp. 268-274, https://www.researchgate.net/publication/49743560_Explaining_the_family_conflict-glycemic_control_link_through_psychological_variables_in_adolescents_with_type_1_diabetes (13.12.2016). 
IBM SPSS Statistics for Windows 21.0, Armonk, New York.

Kobasa S. C., Stressful life events, personality, and health: an inquiry into hardiness, "Journal of Personality and Social Psychology" 1979 No. 37 (1), pp. 1-11.

McCubbin H. I., McCubbin M. A., Resiliency in families: a conceptual model of family adjustment and adaptation in response to stress and crises, in: Family assessment: resiliency, coping and adaptation: inventories for research and practice, eds. H. I. McCubbin, A. I. Thompson, M. A. McCubbin, Madison 1996.

McCubbin M., McCubbin H., Thompson A., FHI: Family hardiness index, in: Family assessment inventories for research and practice, eds. H. McCubbin, A. Thompson, Madison 1986, pp. 124-130.

Nabors L. A., Kichler J. C., Brassell A., et al., Factors related to caregiver state anxiety and coping with a child's chronic illness, "Families, Systems and Health. The Journal of Collaborative Family Healthcare" 2013 No. 31 (2), pp. 171-180.

Northouse L. L., Mood D., Kershaw T., et al., Quality of life of women with recurrent breast cancer and their family members, "Journal of Clinical Oncology: Official Journal of the Amercian Society of Clinical Oncology” 2002 No. 20 (19), pp. 4050-4064.

Pate T., Klemencic S., Battelino T., Bratina N., Fear of hypoglycemia, anxiety, and subjective well-being in parents of children and adolescents with type 1 diabetes, "Journal of Health Psychology" 2016 No. 1-10.

Patterson J. M., Garwick A., The impact of chronic illness on families: a family systems perspective, "Annals of Behavioral Medicine" 1994 No. 16 (2), pp. 131-142.

Pavot W., Diener E., Review of the satisfaction with life scale, "Psychological Assessment" 1993 No. 5 (2), pp. 164-172.

Persson C., Benzein E., Årestedt K., Assessing family resources: validation of the Swedish version of the Family Hardiness Index, "Scandinavian Journal of Caring Sciences” 2016 No. 30 (4), pp. 845-855.

Rolland J. S., Families, illness, and disability: an integrative treatment model, New York 1994.

Spielberger C. D., Gorsuch R. L., Lushene R. E., et al., Manual for the State-Trait Anxiety Inventory, Palo Alto 1983.

Svavarsdottir E. K., McCubbin M. A., Kane J. H., Well-being of parents of young children with asthma, "Research in Nursing and Health" 2000 No. 23 (5), pp. 346-358. 
Watson D., Clark L. A., Tellegen A., Development and validation of brief measures of positive and negative affect: the PANAS scales, "Journal of Personlity and Social Psychology" 1988 No. 54 (6), pp.1063-1070.

Woodson K. D., Thakkar S., Burbage M., et al., Children with chronic illnesses: factors influencing family hardiness, "Issues in Comprehensive Pediatric Nursing” 2015 No. 38 (1), pp. 57-69. 